Chapman University

Chapman University Digital Commons

Education Faculty Articles and Research

College of Educational Studies

2014

\title{
Con Respeto: A Conceptual Model for Building Healthy Community-University Partnerships Alongside Mexican Migrant Families
}

Miguel Zavala

Chapman University,mzavala@chapman.edu

Patricia A. Pérez

California State University, Fullerton

Alejandro González

California State University, Fullerton

Anna Díaz Villela

California State University, Fullerton

Follow this and additional works at: http://digitalcommons.chapman.edu/education_articles

Part of the Bilingual, Multilingual, and Multicultural Education Commons, Chicana/o Studies Commons, Curriculum and Instruction Commons, Curriculum and Social Inquiry Commons, and the Latina/o Studies Commons

\section{Recommended Citation}

Zavala, M., Peréz, P., González, A., \& Diaz-Villela, A. (2014). Con respeto: A conceptual model for building healthy communityuniversity partnerships alongside Mexicana/o migrant families. Journal of Critical Thought and Praxis, 3(2). Retrieved from http://lib.dr.iastate.edu/jctp/vol3/iss2/5 


\section{Con Respeto: A Conceptual Model for Building Healthy Community- University Partnerships Alongside Mexican Migrant Families}

\section{Comments}

This article was originally published in Journal of Critical Thought and Praxis, volume 3, issue 2, in 2014.

\section{Copyright}

Iowa State University Digital Repository 
In this paper, we take on the question of the quality of community and university partnerships that support migrant students' access to higher education. Specifically, we focus on a conceptual model for building healthy community-university partnerships that are both transformative and seeded con respeto (Valdés, 1996). In our critical re-reading of existing scholarship on community-university partnerships, we see the pervasiveness of program planning frameworks, manifest in discourse of evaluation and "effectiveness" used to assess the quality of the partnership. The second pervasive model is what we term a mutual interest framework. As practitioners and scholars, and as advocates seeking to improve the lives of migrant families, we find the need to critically challenge these dominant lenses used to assess the quality of partnerships. It is thus that we turn to the health fields as a point of departure, working our way towards a distinct paradigm that conceptualizes partnerships in terms of interpersonal relations, thus centering health rather than effectiveness or mutual interest.

This article encompasses the first phase of a longitudinal research project aimed at generating resources for educators and student affairs personnel to further support collegegoing migrant youth. This paper is informed by our work with the Migrant Families Conference at California State University, Fullerton (CSUF). Further, from our perspectives as Chicana/o students, educators, program coordinators, scholar-activists, and parents, we outline challenges and practical implications based on this work. To be specific, our goals for this paper are threefold and follow the major sections of this paper: 1) provide background information about the Mexicana $/ 0^{1}$ migrant community; 2) conceptualize a new model to forge healthy communityuniversity partnerships; and 3) discuss challenges that surface in creating new collaborations as well as provide practical implications and enduring questions in response to these challenges.

\section{Background/Context: Understanding Migrant Students' Lives}

\section{Economic Hardships}

\footnotetext{
${ }^{1}$ We use the Spanish term Mexicana/o to emphasize the way Mexican-origin migrant families identify themselves. We prefer the more inclusive use of $-\mathrm{a} / \mathrm{o}$ rather than the gendered term Mexicano.
} 
According to the Office of Migrant Education, in 2012 there were over 850,000 migrant students identified in the U.S., the majority of whom are of Mexican descent and over half residing in California and Texas alone. Scholars have argued that migrant families are a vulnerable community and are among the most severely economically and socially marginalized groups in the country (Lopez, 2001; Lopez, 2004; Lopez, Scribner, \& Mahitivanichcha, 2001; Zalaquett, Alvarez McHatton, \& Cranston-Gingras, 2007). Migrant communities continue to face a multitude of challenges that go beyond the everyday challenges of non-migrant, Mexicana/o families.

Historically, migrant farmworkers have lived isolated from and in the shadows of mainstream culture. According to Branz-Spall and Wright (2004), "Many Americans were deeply stirred by the 1960 Edward R. Murrow documentary Harvest of Shame, which exhibited the strenuous toil, pathetic living conditions, wrenching health and nutritional needs, and miserable poverty of migrant farmworkers in the United States" (p. 2). As documented by Gilbert Gonzalez (2013), Mexicana/o migrant communities have been instrumental to the economic development of the U.S. capitalist system while being relegated and treated as second-class citizens. Once Mexicana/o families were positioned as the labor pool for agricultural production in the southwest, they have been condemned to "poor nutrition, poor health, poor housing, and virtually no education," (p. 126). Further, "The educational experience of migratory children represented the social aspect of the economic system, which established the migrant family as the foundation for its productivity" (Gonzalez G.G., 2013, p. 126). That is, the inextricable link between poverty, deplorable social conditions, poor schooling and outcomes, deeply impacts the economic and social mobility of migrant children. Ironically, in 1927 California was the only state in the southwest that established special funds for migratory schools that catered specifically to child farmworkers where a truncated schedule allowed children to join their family members in the fields (Gonzalez Gilbert, 2013). Despite the Fair Labor Standards Act of 1938, 
which prohibited the use of child labor and set a minimum wage, employers continued such immoral labor practices in the hiring practices of Mexicana/o children.

\section{Access to Education}

It was not until the Elementary and Secondary Education Act of 1965 that the U.S. federal government established funds, services, and definitive guidelines for supporting migrant students, leading to the creation of the Migrant Education Program (MEP). Currently, there are twenty-three MEP regional offices in the state of California. Despite needed services migrant students receive via federal programs (such as the College Assistance Migrant Program $^{2}[\mathrm{CAMP}]$ and High School Equivalency Program ${ }^{3}$ [HEP]), researchers have found that migrant families continue to be marginalized by harsh educational policies (Lopez, 2004). For example, migrant students are among the populations least likely to attend postsecondary institutions (Zalaquett et al., 2007). Previous studies have documented low rates of high school graduation, college preparatory course-taking patterns, and college enrollment among migrant students (see Gibson \& Hidalgo, 2009; Zalaquett et al., 2007). Lopez et al. (2001) pointed to high poverty levels, continuous mobility, and limited English-language skills as conditions that contributed to migrant students' high push out rates and lower academic achievement. As suggested by Nuñez (2009), poor schooling also hinders college access for migrant students. To be specific, migrant students are forced to contend with changing curricula, pedagogical methods that exclude them, and, at times, with different graduation requirements as they move from school to school (Gibson \& Hidalgo, 2009). These factors undoubtedly contribute significantly to the low college enrollment of migrant students.

\footnotetext{
${ }^{2}$ CAMP is a federally funded program designed to support the academic needs of students who are migratory or seasonal farmworkers (or children of such workers) enrolled in their first year of undergraduate studies in participating postsecondary institutions (U.S. DOE, 2014).

${ }^{3} \mathrm{HEP}$ is a federally funded program designed to help migratory and seasonal farmworkers (or children of such workers), who are 16 years of age or older and not currently enrolled in school, obtain the equivalent of a high school diploma (U.S. DOE, 2014).
} 
The struggle to access higher education is connected to the broader struggle migrant families experience, as historically exploited and socially marginalized communities. While migrant farmworkers are the backbone of the annual $\$ 44.7$ billion California farm industry (California Department of Food \& Agriculture, 2014), farmworkers along with miners, are first in occupational mortality rates (National Safety Council, 2010). Farmworker mortality rates are seven times higher than the national average of all occupations (National Safety Council, 2010). Given these facts, migrant students are members of our society's most marginalized and exploited communities.

\section{Student Successes}

In spite of these struggles, key studies have documented the success stories of migrant students graduating from high school and completing college (González A., 2013; McHatton, Zalaquett, \& Cranson-Gingras, 2006; Nuñez, 2009; Zalaquette et al., 2007). Gibson and Hidalgo (2009) examined the impact MEP had on students and found MEP teachers helped close the college enrollment gap through strong, supportive relationships and further, they provided critical information and guidance when applying to postsecondary institutions. Moreover, research has underscored that migrant parents value education and see it as a way out of poverty (González Alejandro, 2013; Lopez, 2001, 2003; Prewitt-Diaz et al., 1989, as cited by Gibson \& Hidalgo, 2009). Along the same vein, Alvarez et al. (2006) looked at characteristics of four-year university migrant students and reported that $78 \%$ of the students identified the family as the driving force behind pursuing higher education. Consonant with research that addresses low academic achievement levels, scholars recommend that schools should "implement and articulate effective educational programs involving the whole family" (Jasis \& Marriot, 2010, p. 138). In a qualitative study with five, first-generation college-going Latinas of farmworker backgrounds, Graff, McCain, and Gomez-Vilchis (2013) noted that family support, academic resilience, and a hard work ethic made it possible for these women to pursue higher education. Finally, in his qualitative study of migrant parents, Alejandro González (2013) found that 
community resources were critical in maximizing higher education opportunities for their children and further reported that MEP served as a bridge or what the author referred to as "a bank of resources" to support their children's postsecondary goals (p. 115). In his study, Alejandro González (2013) highlighted the critical role that CAMP played in linking the migrant community to higher education. That is, parents voiced that CAMP was their only connection to higher education. This study, among others, underlies the urgent need to establish communityuniversity partnerships that address the migrant youth's access to higher education.

\section{Methods}

In 2011, students, staff, and faculty at California State University, Fullerton (CSUF), alongside MEP staff and program coordinators, migrant parents, and community members organized the first annual Migrant Families Conference. The conceptual model we develop in this paper is grounded in our experiences organizing the Migrant Families Conference, a daylong, yearly conference for migrant families aimed at facilitating a college-going culture, and providing college resources for migrant children of all ages in Migrant Region IX, serving Orange and San Diego counties in California. To note, approximately $90 \%$ of migrant students served by MEP in Region IX are of Mexicana/o descent (E. Silva, personal communication, January 9, 2014). We draw on our involvement and experiences for at least five months each year between 2011 and 2013 organizing, attending planning meetings, evaluating, and selfreflecting, on the day-long conference, now four years running.

In developing a conceptual model for understanding community-university partnerships, we use our experiences and narratives as a resource for building theory and challenging existing frameworks and lenses. In the spirit of grounded theory (Glaser, Strauss, \& Strutzel, 1968; Strauss \& Corbin, 1990), we employ an interpretive strategy that includes two intersecting methodologies, i.e. autoethnography and narrative research. Chávez (2012) describes autoethnographic research as a "method [that] uses one's own experience in a culture to look at our culture and ourselves (p. 341). Further, Chávez (2012) posited, "Autoethnography confronts 
and defies traditional investigative methods" (p. 342). That is, autoethnography centers researcher positionality and acknowledges that we bring our "cultural intuition" to bear on the phenomenon we are investigating (Delgado Bernal, 1998, p. 568). Delgado Bernal (1998) defines cultural intuition as "a complex process that is experiential, intuitive, historical, personal, collective and dynamic" (p. 568). Moreover, drawing from our own reflections and on-going discussions from the standpoint of coordinator, student, faculty and activist-scholars, we use a narrative strategy (Casey, 1995) for illustrating the ways in which dimensions of healthy community-university partnerships are forged. These narratives, which function as both illustrative stories and systematic reflections, are grounded in our own praxis, yet are interconnected with our engagement with other scholarship, in particular the conceptual and theoretical developments of existing research that is critical of community-university partnerships (Alemán, Delgado Bernal, \& Mendoza, 2013; Alemán, Pérez-Torres, \& Oliva, 2013; Carmona \& Delgado Bernal, 2012).

As children of im/migrant Mexicana/o families and advocates for migrant youth, we contend with negotiating our "insider" perspective (Mercer, 2007; Zavella 1993), while being cognizant that via our institutional roles we remain "outsiders" who have conferred "status" (Baca Zinn, 1979; Collins, 2004). Yet, it is within this "insider-outsider" positionality-being marginal as scholars of Color committed politically and ethically to working alongside migrant families yet "outsiders" given the privileges we carry by virtue of the institutional positions we represent- - that we are able to tell our story. Along this vein we offer brief narratives of our backgrounds and how we came to engage in this work in the following section.

\section{Positionality}

Alejandro. I grew up in a family that was constantly challenged financially. This neverending threat negatively impacted the future of my three oldest siblings. Necessity forced them to drop out of high school and to exchange their long-life dreams for a weekly paycheck. However, their costly decision to contribute financially to the family and help ends meet allowed 
me to take full advantage of the educational opportunities available. Even though my educational accomplishments will never balance the sacrifices made by my family, I proudly and with great honor share my success with them by acknowledging their struggles with decency and the upmost respect. Because of what I have gained due to my family's many sacrifices, I feel an obligation to help transform lives and futures of those who travel and have traveled the same path I once did. This promise has motivated me to serve migrant families as coordinator for MEP. I have been fortunate to serve this marginalized yet honorable community for the past 12 years. Who I am professionally has been shaped by many life lessons I have learned alongside migrant families. Their struggles are my struggles, and it is this positionality that guides my work and inspires me to continue to serve this community.

Anna. My connection with migrant families was sparked by own family history. As part of the small agricultural rancho of Gavilán Grande, Nayarit, México, I have always been part of the land and the struggles that come with working the soil. For three generations, the Villela family has cultivated beans and tobacco for private and local buyers. As an active member of M.E.Ch.A. (Movimiento Estudiantil Chicana/o de Aztlán) de CSUF during my undergraduate years, I came to learn about the United Farm Workers movement and struggles of organizing led by Dolores Huerta and Cesar Chavez. As a MEChistA, I have been heavily involved in the organizing committee and as a conference participant. I was overwhelmed with the reality that my migrant brothers, sisters, and families were still living through injustices in the areas of education, labor, and basic human rights. Using the philosophy I learned from M.E.Ch.A.'s founding documents and my personal experiences, it is necessary for me to continue to help those families and students who are from the most marginalized communities: migrant youth and families, undocumented students, and delinquent youth and young adults.

Miguel. It was at a later stage in my life, when working as an instructor (2003 - 2005) for the Migrant Student Leadership Institute at UCLA, a program that seeks to empower migrant students, that I learned of my cultural history and my own families' ties to the land. While my 
mother and father have been bound to industrial work, having migrated to the U.S. during the 1960s and both laboring in the local industry of Los Angeles, our family's connection to the land continues. On my father's side, the vast majority has found a second home in the Central Valley in California and in Rio Grande Valley in southern Texas, working the fields picking grapes and other seasonal crops. While our my family's history is one of economic exploitation, the centrality of educación in the family and education at school is always present to this very day and fuels my own involvement and commitment to the migrant community, now as a professor at CSUF and an active member of grassroots organizations such as the Association of Raza Educators (ARE). I see so much potential in the institutional role I play as faculty, being able to leverage resources in the service of migrant families. It is thus that I have sought building with faculty and community members driven by a sense of restorative justice for migrant families, who I regard as the most exploited group in the U.S.

Patricia. It is no surprise that I gravitated towards and worked for the Migrant Student Leadership Institute from 2003-2004 as a program coordinator while a graduate student at UCLA given my familial background; and now as a faculty member in a Chicana and Chicano Studies department at CSUF, I continue to support and advocate on behalf of im/migrant communities. Like the migrant families we work alongside, I come from a long heritage of hard workers. For example, my grandfather, a participant in the Bracero Program, ${ }^{4}$ worked in agricultural fields across Arizona, Texas, and California. My father toiled in el sacate ${ }^{5}$ and later spent decades in the construction industry. My maternal and paternal grandmothers raised nine and 13 children, respectively. What my grandparents and parents had in common was that they wanted better opportunities for their families. Understanding education was key to a better life, my family laid a foundation that would encourage and facilitate my path to and through higher education. As a first-generation college student, I felt it important to assist other students like

\footnotetext{
${ }^{4}$ A temporary guest worker program for Mexican nationals that ran from 1942 to 1964. In the Spanish language, "Bracero" refers to "one who works with his arms.".

${ }^{5}$ Spanish for grass.
} 
myself because I did not arrive here alone. I am selfishly drawn to work with Latino youth and families from immigrant and migrant backgrounds to honor the familial sacrifices made on my behalf.

\section{Towards a Model of Healthy Community-University Partnerships}

\section{Dominant Frameworks}

In investigating and exploring the central theme of this study on how we build healthy community-university partnerships with and alongside migrant families, we turn to existing studies and the burgeoning literature on community-university partnerships. In this review we move conceptually, drawing out salient approaches to the question of the quality of communityuniversity partnerships, thus working our way towards a framework and argument for healthy community-university partnerships. Our conceptual model points to fundamental dimensions of healthy partnerships drawn out from the existing literature. Yet, in developing this new framework, we build on the concept of respeto (Valdés, 1996) as a central component in healthy partnerships: respeto, while usually defined by the Mexicano community as intrinsic to familial and close relationships, is richer than its English translation. Respeto in its Spanish usage is fundamentally about the recognition of the presence of people and, we argue, entails the full recognition of migrant families' struggles, aspirations, hopes, and dreams.

In our review of studies on community-university partnerships, we note how the question of the quality of community-university partnerships has been framed as a question of effectiveness. Thus, a fundamental question underlies these studies: What are the conditions that make these partnerships effective? Digby et al. (1993) identify four key elements in effective partnerships between educational institutions and underserved communities: commitment, communication, concern, and compromise. Furthermore, in the literature we have found what we term a mutual interest and development model that can best be summarized as the process by which community-university partnerships support the goals and missions of partnering organizations. Holland and Gelmon (1998) argue, "Effective partnerships are 
knowledge-based collaborations in which all partners have things to teach each other, things to learn from each other, and things they will learn together" (p.107). The partnership itself must, therefore, lead to the development of each individual entity involved in that partnership: "An effective partnership builds the capacity of each partner to accomplish its own mission while also working together" (p. 107). This approach and assessment of what makes effective community-university partnerships is echoed by Bringle and Hatcher (2002): "Successful campus-community partnerships must find ways to preserve the integrity of each partner and, at the same time, honor the purpose of the relationship and the growth of each party" (p. 513). While agreeing with the general premise that partnerships should lead to the development of each partnering organization, we argue for an asset-based model of community-university partnerships, re-positioned within a transformative framework that emphasizes not just mutual interests but the authentic transformation of each partner. Given the denial of access to higher education and the subtractive nature of schooling for Mexican-origin students (Acuña, 1988; Valenzuela, 1999; Yosso, 2006, 2005), transformative partnerships with Mexicana/o migrant families should also lead to the transformation of the university. Moreover, partnerships themselves should lead not just to the development of each respective partner but also the partnership itself. A limitation in seeing the development of partnering organizations within a mutual interest lens is that it limits what is possible when these different and often divergent groups come together. While partnerships lead to the development of each organization, the partnership itself is, we argue, a social, people-people relationship that is to be nurtured and seeded con respeto.

Thus, we characterize the effectiveness framework as a dominant model for assessing the quality of community-university partnerships. We propose an alternative and what we believe is a more comprehensive and transformative framework. Emphasizing the health of the partnership in dynamic ways, this partnership should lead to the development of the university, the migrant community, and the partnership itself. 


\section{Why A Different Conceptual Model?}

In theorizing a new model of healthy community-university partnerships, we build upon Bringle and Hatcher's (2002) general framework on healthy relationships which identifies the following key dimensions: trust, reciprocity, mutual respect, closeness, healthy interdependency, and affirmation. While this framework is quite broad, we find it useful in our attempt to build an alternative working model for thinking about community-university partnerships in a holistic and humanizing way. Based on our collective experience advocating for migrant families, we explore the following dimensions in articulating a new model of healthy community-university partnerships: trust, reciprocity, interdependence and validation (See Figure 1). Indeed, for migrant Mexicana/o communities, the question of health and healthy relationships needs to be placed at center, especially given the historical legacy of colonialism, institutional neglect, and marginalization (Acuña, 1988; Almaguer 1974; Gonzalez, Juan, 2011; Spring, 1994). Within a de-colonizing framework (Hérnandez-Wolfe, 2013; Villanueva, 2013), this question of health and healthy relationships is viewed as part of the migrant community's own historical survival, recovery and healing processes.

Our collective reflection argues not just for a relational model of collaboration. Rather, we illustrate, in the vein of grounded theory (Glaser, Strauss, \& Strutzel, 1968; Strauss \& Corbin, 1990), how the aforementioned dimensions are mediated in our own practical work organizing and building with migrant families. We approach our reflection with the recognition that "developing a working relationship is a shared and evolving process" (Srinivasan \& Collman, 2005, p. 1815). Drawing from the disciplines of health with an eye towards building healthy (distinguished from effective) community-university partnerships in collaboration with migrant families, we offer a working definition for each dimension, how this particular dimension is fostered, and what it looks like within the context of our work with migrant families.

\section{Narrative Vignette: Striving for Healthy Partnerships}


What follows is a collective narrative that centers on the pre-planning and planning phases in organizing our second annual Migrant Families Conference. The narrative includes different moments that we have chosen from our field notes that we find assist readers in illustrating the different dimensions of healthy community-university partnerships. In the spirit of autoethnography, these narratives include our own lived experience as a resource for generating knowledge. They were developed collectively through our recollection of events as they unfolded-we do not purport to include the experiences of migrant families here. Eventually, we expand on the narrative vignette to include a working definition of each of the model's dimensions (i.e., trust, validation, reciprocity, interdependence).

Pre-planning stages. Following the introduction of the idea of a conference in 2010 by university faculty seeking to support migrant students, the MEP coordinator and parent leaders expanded this idea into a comprehensive conference that was to include not just students but migrant families. After many visits, where the idea was taken to the homes of migrant families, the plan began to crystalize. To further the discussion and promote inclusion of all migrant families in the Orange and San Diego County areas, data pertaining to migrant student college and university enrollment were shared in Parent Advisory Committee meetings. After discussing the need to increase the number of migrant students accessing higher education institutions, the parents decided to support the organizing of a conference.

Fieldnote entry. Parent representatives met with the coordinator, local community members, university faculty, and college students on a Saturday morning over pan dulce and coffee at the Region IX Orange County office. During this discussion, one college student asked parents what workshops they wanted to see. The parents responded with “¿Y ustedes que piensan?” (Well, what do you think?). The students countered with, “QQué quieren saber?” (What do you want to know?). What ensued was a question and answer period where students were asked to share their experiences, what college was like, how they financed school, and how they were able to make it through college. The 
two university professors in the room were noticeably quiet and only shared their ideas once solicited. Everyone contributed ideas for potential workshops, which were then noted, on poster paper by a student. From the list, parent representatives were asked to go back to their communities and ask other migrant parents what they thought would be most helpful topics to cover at the conference. The goal for the next planning meeting was to narrow down workshop themes.

Planning stages. Already in our second year planning the conference, a recurring tension was felt during the planning meetings where migrant parent leaders looked to CSUF faculty and the MEP program coordinator for direction in defining the content of the conference. Rather than define for themselves the kinds of topics and issues impacting migrant families, parent participants often recurred to those of us positioned as "experts" or as "leading" the planning of the conference. Attuned to this tension, the MEP program coordinator opened a space during one of the meetings that not only allowed parent participants' input, but also by design, privileged their voices in developing conference themes and workshops. We recall here a planning meeting in which migrant parents, student organizers, and CSUF faculty participated.

Fieldnote entry. After introducing ourselves and in the presence of parent representatives from various Orange County districts, who were silent throughout, the MEP program coordinator interjected and said, "Ustedes tienen que decir cuales talleres son imporantes para sus familias... ¿Qué temas quiéren ver en la conferencia?” (You have to say which workshops are important for your families... What themes do you want to see in the conference?). There was a prolonged silence. "Haber Señor Montaño, qué piensa usted, como lider de su distrito?" (Let's see Mr. Montaño, what do you think, as leader of your district?). Mr. Montaño proceeded with a personal story about his daughter and the struggles she faced in accessing college. One significant point he made was the fact that his daughter didn't have knowledge of college 
admissions requirements, specifically the kinds of courses students have to take in high school as they transition into college.

Reflecting on our praxis. The following fieldnote entry highlights tensions generated when working as institutional representatives. Our own reflections stress the ongoing need to check institutional power with democratizing processes that allow migrant families to take ownership over institutional spaces that often marginalize them. These reflections were integral to our critical reframing of traditional notions of partnerships and, therefore, our conceptualization of a partnership model grounded in respeto.

Fieldnote entry. As representatives of institutions, i.e., CSUF and MEP, we have grown cognizant of the tension organizing the previous year's conference, how migrant families develop a relation of dependence upon university faculty or what they regard as "officials" and "experts." During side conversations we also recognize the institutional imbalance of power and how our voices carry more weight in making decisions. How can we assume a listening rather than speaking posture that allows the parents alongside with college student organizers to begin taking the lead in designing the content of the program during the second year of planning? How do we not reproduce the circle of silence that Paulo Freire speaks about or the ways universities trample over marginalized communities?

Trust

Chavez, Wampler, and Burkhart (2006) define trust as "a key component of social capital, which links individuals to 'like' communities through 'bonding' social capital as well as to 'different' communities through 'bridging' social capital” (p. 1012). Using Robert Putnam's extensive work on social capital and the interconnectedness among social networks that result in the norms of reciprocity and trustworthiness as a guide to define trust with migrant seasonal farmworkers, Chavez et al. (2006) conclude that "lower levels of trust are a major concern because they suggest that we may be creating a subclass within the United States" (p. 1026). 
Furthermore, and perhaps more alarming, these researchers suggest that as a result of establishing rapport with migrant families based on trust, because of the structural labor conditions that define migrant farmworkers as "human capital," we are perpetuating a "rural underclass that is not connected to American society" (p. 1026).

While most Mexicana/o migrant families have little formal education, they are rich in educación (González Alejandro, 2013). Understanding the gap between education and educación (which, in its Spanish usage, includes not just knowledge but values and ways of conducting one's self) is critical when attempting to build and foster a relationship rooted in trust. Understanding this cultural difference and building on migrant families' funds of knowledge (Moll, Amanti, Neff, and Gonzalez, 1992) can benefit universities attempting to establish a relationship with this underserved community. Failing to recognize the importance of educación and Mexicana/o migrant families' "richness" and knowledge will work against establishing a genuine relationship grounded in trust. Establishing and maintaining trust with the Mexicana/o migrant community is manifest in a relationship of reciprocity and mutual respect between the MEP and migrant families. As the narrative vignette shows, in order to build trust, the MEP coordinator conducted extensive home visits with migrant parent leaders.

\section{Validation}

According to Rendón (2002; 1994), affirmation and support are considered examples of validation within the context of student development. As defined by Rendón (1994), validation is "an enabling, confirming and supportive process initiated by in- and out-of-class agents that fosters academic and interpersonal development" (p. 44). Further, to summarize, the theory of validation consists of six elements: 1) initial contact is initiated by institutional agents; 2) students feel like capable learners and recognize their self-worth; 3) validation is the precursor to student development; 4) validation can take place in and out of class with anyone; 5) it is a process; and 6) validation experiences are crucial early on in the students' postsecondary experience (Rendón, 2002). 
Cultural validation theory (Rendón, 1994) between university agents and students from non-dominant communities can serve as a guide to frame validation between migrant parents and university constituents. In rethinking our relation to migrant families, we build upon a central principal of Rendón's (1994) validation theory, namely that institutions and their representatives must be proactive in creating spaces of validation for culturally diverse students. This process of validation, however, must be dialogical in the sense that both university representatives and migrant students (and families) take part in this process—so that we do not reproduce the idea that validation only takes place when institutions take up such a process.

In a deliberate manner, migrant parent leaders were integral to the conference organizing committee. In fact, the agenda, workshops, and schedule were framed around their requests. As a result, their struggles, stories, and experiences that motivated them to provide better educational opportunities for their children were affirmed. Subsequently, once parents felt validated (or more pressing, that we, as institutional representatives, were not proceeding with a posture of invalidation), migrant parents were quite vocal in how the Migrant Families Conference could address their needs of attaining concrete knowledge about higher education (particularly in their native language of Spanish). In authenticating their experiences, language, and meeting them in spaces they felt comfortable in, communication organically improved through mutual acceptance and respect.

\section{Reciprocity}

Reciprocity is often touted as one of the key components of healthy communityuniversity partnerships, emphasizing collaborations that are mutually beneficial and egalitarian (Henry and Breyfogle, 2006; Kecskes, 2006). However, scholars have argued that reciprocity, often discussed in the service learning and community engagement literature is left undefined (Clayton, Bringle, Senor, Huq, and Morrison, 2010; Dostilio et al, 2012). Despite fluid or assumed definitions, scholars agree reciprocity is instrumental in establishing sustainable and 
transformative community-university partnerships (d'Arlach, Sanchez, and Feuer, 2009; Jameson, Clayton, and Jaeger, 2010).

In our narrative vignette, the reciprocal relationship is demonstrated through the new knowledge base that is created for each of the partners in this collaborative space. According to Dostilio et al. (2012), these spaces create "the possibility for new and different ways of being, processes, and outcomes to emerge" (p. 25). Indeed, without having had the migrant parents as collaborators (and all other partners for that matter), the Migrant Families Conference would have been planned, looked, and felt very different. Further, hierarchies between players are leveled when all parties are viewed and treated as equal partners. That is, status differences (as a result of "formal education," language, citizenship status, for example,) are minimized so that the mutually beneficial, reciprocal relationships can flourish (Dostilio et al., 2012).

Dostilio et al. (2012) describe reciprocity as "framed and structured in a variety of ways, including as a function of epistemology, identity, relationship qualities, and power" (p. 21). Further, they outline three types of reciprocity orientations: exchange, influence, and generativity. In exchange-oriented reciprocity, there is a give and take of resources; in influence-oriented reciprocity, the dynamic between participants is altered as a result of the partnership and is informed by their context; and finally, generativity-oriented reciprocity is described as the "interrelatedness of beings and the broader world around them as well as the potential synergies that emerge from their relationships" (Dostilio et al., 2012, p. 24). While they do not advocate for a particular orientation, they make clear that multiple forms of reciprocity can coexist. The narrative vignette, while illustrative of exchange-oriented and influenceoriented reciprocity, does not preclude elements of generativity-oriented reciprocity. Ideally, partnerships rooted in healthy reciprocity engender an underlying transformative element that empowers all parties and leads to future collaboration: "This is a shift in conceptualizing relationships within service-learning as 'how we are together' versus 'what we do together'..." (Dostilio, 2012, p. 25). Ultimately, reciprocity can be qualified as a process, outcome, or both, 
and can influence what participants do and how they are towards one another (see Dostilio et al., 2012).

\section{Interdependence}

In their review of core documents and reports on building and sustaining more collaborative community-university partnerships, Gilbert, Johnson, and Plaut (2009) note the general absence in articulating efforts to "cultivate a sense of interdependence among partners" (p. 36). They see this as an issue especially because universities and communities "operate within the same set of social, economic, and political systems," sharing "an interest in and a responsibility for creating conditions that allow people to thrive" (p. 36). While not the only quality in the development of collaborative partnerships, they argue for interdependence as a dimension central to sustainable partnerships. Though we do not disagree with Gilbert, Johnson, and Plaut's (2009) general analysis of the inter-dependent-or more accurately, interrelational—condition between institutions such as universities and historically underserved communities, we note the absence of a definition of interdependence here and in the general literature on community-university partnerships.

We believe that interdependence is shaped through exercises in collaborative work, as illustrated in our narrative vignette. Trust is also built through the very process of jointcollaboration, thus leading to our understanding that as institutional agents and representatives we are novices, not experts, in the lives of migrant farmworkers. It is this recognition and listening disposition that enables us, as agents occupying spaces of privilege and power, to recognize what Paulo Freire characterizes as our "unfinishedness" (Freire, 2000). We are limited in our capacities of knowing, and this recognition requires a level of humility that is necessary in building interdependently.

How has interdependence been defined in the literature on community-university partnerships? Enos and Morton's (2003) articulation of interdependent partnerships represents an attempt to define interdependence by contrasting it with "mutual dependence": "As the 
partners come to believe that they share a common domain, that each contributes experience and knowledge, their relationship becomes based on interdependence rather than mutual dependence" (p. 30). But what exactly is meant by mutual dependence? Interdependence seems to suggest mutuality or some form of reciprocity, where some common ground is fostered, which itself leads to the development of each partnering member. Yet, when we look to health fields, a more fully developed conception of interdependence is rendered, a conception that informs the emerging framework of healthy partnerships.

Within the health fields, in particular clinical psychology, interdependence is contrasted with co-dependence, a construct that is quite varied but can mean such things as fear of abandonment and focus on others while denying one's own needs (see Le Poire, Hallet, \& Giles, 2009). Quick and Macik-Frey (2007) argued "Interdependence enables individuals to appropriately draw upon the positive resources within a social support system that lead to vitality and well-being" (p. 36).

\section{Challenges to Fostering Healthy Partnerships}

There were clear tensions that emerged when forging healthy community-university partnerships between all partners involved, partially captured in the narrative vignette. Although not exhaustive, we address some of the significant challenges that surfaced from our vantage points as faculty members, MEP coordinator, and college student. Herein, we identify four major challenges in developing healthy university partnerships with migrant families-many of these challenges have been well documented in other scholarship attune to tensions, and contradictions created by differentials of power (see Anyon, 2005; Bringle \& Hatcher, 2002; Freire, 2000; Greenberg, 2000; Holland \& Gelmon, 1998; Mora \& Diaz, 2004; Smith, 1999; Zavala, 2013).

\section{Institutional Paternalism}

The first tension is the problem of voice and participation in relationships that are unequal by virtue of power conferred upon institutions and their representatives. In working with 
historically underserved communities, this dilemma has been a persistent one, where on the one hand we have universities attempting to build with and support underserved populations, yet in that very process reproduce or exacerbate structural inequality. Within the field of education and action research this has been well documented and can be summarized as a paternalistic, top-down model of knowledge production (See Freire, 2000). In line with this impasse, Holland and Gelmon (1998) argue, "As academics, we are trained as experts and tend to imagine community partnerships in which the institution identifies a need and offers an expert solution to an otherwise apparently hapless (or hopeless) community" (p. 105).

\section{Moving From Charity to Self-Determination}

A second challenge emerges by virtue of the different long-term goals each partner brings to the planning table. Especially because universities are imbued with power and are interlocked with broader interests that seek to maintain the status quo (Olssen \& Peters, 2007; Zavala, 2013), their relation to migrant families is not only paternalistic but, often, exploitative. University goals such as the procurement of funding and institutional legitimacy may trump the development of the aspirations, vision, and health of the migrant community itself. This problem has been manifest (and obfuscated) as a posture of charity, where the university or institution justifies its "assistance" or "service" to underserved populations while leaving the conditions of inequality, injustice, poverty, exploitation, racial discrimination, etc., untouched (Bringle \& Hatcher, 2002). In contrast to charity models, Marullo and Edwards (2000) argue for a restorative justice partnership model that in their words strategically "alter[s] institutional arrangements by redistributing resources and enhancing capacities of those with less, so that such institutional operations no longer maintain such inequities" (p. 898). Thus, they argue for a partnership model that moves beyond providing "services" to those in "need" to a model that "redistributes" resources from institutions to communities with the goal of transforming those very institutions that perpetuate inequality. A fundamental dimension of restorative justice 
partnerships is to "solve social problems rather than simply ameliorate their negative consequences" (p. 899).

\section{Not Enough Time To Build Authentically}

A third reoccurring challenge is the limited time available to engage in meaningful partnerships and service activities that grow out of authentic, reciprocal relationships. As university faculty working in primarily teaching institutions, we are forced to limit our time in service activities or jeopardize tenure. Devaluing authentic collaboration with marginalized groups, we find ourselves limited and overextended, unable to sustain a healthy interdependence that requires time, effort, and collective praxis. And when collaboration is enacted it is usually mediated by large grants that themselves inflect the goals of larger institutions or foundations, which often benefit more than the communities they purport to serve (see Anyon, 2005; Greenberg, 2007). Further, the pressure to publish and heavy teaching loads taints our relationship with migrant families. For example, faculty who are able to engage in collaborative activities are placed in a position where the service activity is appealing mostly because it can be used as a data collection site for future research. Herein, prioritizing research transforms the power dynamics and sets limits to the partnership: when the research funding ends, the relationship also dissipates.

Despite these constraints relative to time, it is common for faculty of Color to engage in extensive service activities (Ponjuan, 2011). However, it is no surprise that in the first two years of collaboration, faculty involved in this project limited involvement to planning and organizing the Migrant Families Conference. It was not until planning for the third annual daylong conference that we would engage in discussions about a student residential program that would require a much larger commitment. By this third year, one faculty had already received tenure and the other would be submitting his case for tenure the following year.

The second tension relative to time is tied to federal eligibility requirements that prohibit the use of more than three years of MEP services. Such a short time period is not conducive to 
forging reciprocal and authentic partnerships with migrant communities. Working within such a constraint, the new challenge then becomes how to sustain the partnership and create interdependence so the community engenders self-determination.

The final tension relative to time stems from the challenge of home visits. One of MEP's approaches to building trust with the migrant community is by providing valuable services to the families. Lopez (2004) suggests that migrant families benefit most when services are provided through home visits; however, regularly visiting and establishing a rapport with every family is a challenge. Due to work schedules, most families are not available until late evenings. Because of this limitation, the MEP encourages and does everything possible to have all families attend the Parent Advisory Committee meetings where information is shared and community input is solicited.

\section{Migrant Families' Previous Negative Experiences With Outsiders}

A fourth and final challenge addressed here stems from anti-immigrant ideologies, hostility, and the politically charged atmosphere we are facing today. Such an environment has made migrant families distrustful of institutional representatives. Additionally, we have found that previous negative interactions with private vendors selling expensive college resources have negatively impacted the participation of other migrant families in the conference and other events. As a result, initial distrust is common within the migrant community, thus making collaboration with institutions difficult. Although the MEP reinforces that any event provided or sponsored by MEP is free to all migrant families, it takes sustained closeness and commitment to gain their trust.

Second, it is not uncommon for communities of Color to experience drive-by research (Mora \& Diaz, 2004; Smith, 1999). Initial distrust of researchers, who are often faculty and other university representatives, makes developing authentic relationships especially difficult. This may make creating trust just as complicated. That is to say, migrant families may initially reject 
advocates and allies because of the institutions they represent based on their previous negative experiences with exploitative research.

\section{Addressing Barriers to Building Healthy Partnerships}

\section{Re-Generating Trust through Respeto}

Through a reflective analysis of the process of establishing trust with Mexicana/o migrant parent leaders in organizing the Migrant Families Conference, three approaches were recognized as critical for a healthy partnership. First, and perhaps most significant, is the importance of fostering dialogue where parents are not only encouraged to share their perspectives but decision-making protocols are established that make their input the driving force of planning. This, if not done genuinely, can deter from building trust with Mexicana/o migrant families. Second, meetings and all planning sessions must be offered at convenient times for families. Being accessible when Mexicana/o migrant families are available is crucial. Lastly, assigning tasks that supports their involvement is important. Assignments must be shared equally and fairly so that everyone's skills, strengths, and resources are utilized appropriately and strategically. This can help eliminate migrant families from deferring and depending on "experts" for advice.

We believe that trust is built through a genuine approach that is inclusive and done con respeto (Valdés, 1996). This also encourages and promotes mutual respect between migrant families, universities, and federal programs that seek to support the academic prosperity of this community. It is also important to recognize that through a partnership grounded in trust, migrant families and universities and/or other programs can genuinely work together on the academic needs of migrant children in a respectful manner.

\section{Modeling Respeto and Ideological Change}

As institutional representatives, it is vital that we model and embody principles of respeto and that we ourselves are committed to ideological change. If we seek the development of healthy community-university partnerships, we should of course, as individuals, strive for 
psychological and emotional well-being—which necessitates constant reflection and humility. If we are to break the paradigms of paternalism and charity work, two important moves are needed. The first is that that we develop a critical understanding of the way institutions operate. While we may see ourselves as advocates for migrant families, having a keen, historical understanding of the contradictions inherent in federal, state, and private institutions and their relation to migrant communities is vital. This keen awareness should allow us to see limits in what is possible when partnering with institutions, but these limits should not determine what the goals and outcomes of partnerships entail-it is the migrant families themselves, their dreams, hopes, and aspirations, which should drive partnership goals.

Moreover, while paternalistic, top-down approaches and charity models pervade community-university partnerships, as individuals we have the capacity to challenge these frameworks on many levels. Personally, we must be reflexive of how we embody these discourses. We believe that modeling respeto in our own conduct becomes a bridge that allows us to build authentically and in healthy ways with migrant families.

\section{Conclusion}

As we continue to foster trust, validation, reciprocity, and interdependence vis-à-vis concrete projects such as the Migrant Families Conference, we continue to generate respeto, working with and alongside migrant families. While we recognize this model of communitybuilding is not devoid of contradictions, we take the risk involved in building authentically-a risk that we believe and hope will lead us to better, humanizing spaces of health and healing for Mexicana/o communities. Grounded in our lived-experience as partners working alongside migrant families, we also see limits to the proposed framework that privileges health and wellbeing, which sees community-university partnerships as people-people relationships rather than relations between abstractions, such as "universities" and "the migrant community." As we further expand upon this model through our continued practical work, future research will 
integrate the voices of migrant families themselves, thus enriching the framework of healthy community-university partnerships.

To summarize, we offer the following working definitions for each dimension of healthy community-university partnerships:

Trust: Sustained closeness, where mutual parties build a personal awareness of each other as people, thus establishing confianza ${ }^{6}$ and a mature understanding and agreement of the partnership.

Validation: A means of acknowledging the struggles, context, and input of partners and their active involvement in organizing and planning that meets their needs and goals. Reciprocity: Transformative in nature by leveling the power dynamics of participants, where the exchange of resources is mutual and restorative, thus generating new ways of collaborating and being.

Interdependence: Collaborative and respectful relationships between partners, transformative rather than simply transactional in their exchange and generation of knowledge and resources, and embodying reciprocity that fosters the transformation and development of partnering organizations, individuals, and the partnership itself.

\section{Enduring Questions}

We conclude our discussion with a set of questions for practitioners, researchers, scholar-activists, and advocates of migrant families.

- In what ways do our partnerships deliberately foster healthy interdependence, reciprocity, validation, and trust?

- Are we reflexive of the challenges presented by the discourses and practices of institutions, such as universities, that set limits to how we both view partnerships and how we enact these?

\footnotetext{
${ }^{6}$ Spanish for rapport.
} 
- How do our reflections both engender health and well being in our selves and in our practical work?

- What do healthy community-university partnerships look like from the vantage point of migrant parents?

- What strategies can communities and universities enact to sustain these partnerships in the short and long-term? 


\section{References}

Acuña, R. (1988). Occupied America: A history of Chicanos. New York: Harper \& Row.

Alemán, E., Delgado Bernal, D., \& Mendoza, S. (2013). Nepantla in our community-based praxis. In M. Lynn \& A.D. Dixson (Eds.), Handbook of critical race theory in education (pp. 325 - 338). New York, NY: Routledge.

Alemán, E., Pérez-Torres, J. C., \& Oliva, N. (2013). Adelante en Utah: Dilemas of leadership and college access in a university-school-community partnership. Journal of Cases in Educational Leadership 16(3), 7 - 30.

Almaguer, T. (1974). Historical notes on Chicano oppression: The dialectics of racial and class domination in North América. Aztlán: A Journal of Chicano Studies 5(1-2), 27 - 56.

Anyon, J. (2005). Local challenges to federal and regional mandates. In J. Anyon, Radical possibilities: public policy, urban education, and a new social movement (pp. 111 - 123). New York, NY: Routledge.

Baca Zinn, M. (1979). Field research in minority communities: Ethical, methodological, andpolitical observations by an insider. Social Problems, 27(2), 209-219.

Branz-Spall, A.M. \& Wright, A. (2004). A history of advocacy for migrant children and their families: More than 30 years in the fields. In C. Salinas \& M. Fránquiz (Eds.), Scholars in the field: The challenges of migrant education (pp. $2-10$ ). Charleston, WV: ERIC Clearinghouse on Rural Education and Small Schools.

Bringle R. G. \& Hatcher, J.A. (2002). Campus-community partnerships: The terms of engagement. Journal of Social Issues, 53(3), 503-516.

California Department of Food and Agriculture (2014). California agricultural statistics review: 2013 - 2014. Sacramento, CA: California Department of Food and Agriculture.

Carmona, J.F. \& Delgado Bernal, D. (2012). Oral histories in the classroom: Home and community pedagogies. In C. E. Sleeter and E. Soriano (Eds.), Creating solidarity across diverse communities: International perspectives in education (pp. 114-130). New York, NY: Teachers College Press.

Chávez , M. (2012). Autoethnography, a Chicana's methodological research tool: The role of storytelling for those who have no choice but to do critical race theory. Equity \& Excellence in Education 45(2), 334-348.

Chavez, M., Wampler, \& B. Burkhart, R. (2006). Left out: trust and social capital among seasonal farmworkers. Social Science Quarterly, 87, 1012-1029.

Clayton, P., Bringle, R., Senor, B., Huq, J., \& Morrison, M. (2010). Differentiating and assessing relationships in service-learning and civic engagement: Exploitative, transactional, or transformational. Michigan Journal of Community Service Learning, 16(2), 5-22.

Collins, P. H. (2004). Learning from the outsider within: the sociological significance of black feminist thought. In S. Harding (Ed.), The feminist standpoint theory reader (pp. 103126). New York, NY: Routledge.

d'Arlach, L., Sanchez, B., \& Feuer, R. (2009). Voices from the community: A case for reciprocity in service-learning. Michigan Journal of Community Service-Learning, 16(1), 5-16.

Delgado Bernal, D. (1998). Using a Chicana feminist epistemology in educational research. Harvard Educational Review, 68(4), 555-582.

Dostilio, L., Brackmann, S., Edwards, K., Harrison, B., Kliewer, B., et al. (2012). Reciprocity: Saying what we mean and meaning what we say. Michigan Journal of Community Service Learning, 19(1), 17-32.

Enos, S. \& Morton, K. (2003). Developing a theory and practice of campus-community partnerships. In B. Jacoby (Ed.), Building partnerships for service-learning (pp. 20 41). San Francisco, CA: Jossey-Bass.

Freire, P. (2000). Pedagogy of the oppressed. New York: Bloomsbury Academic. 
Gibson, M. A., \& Hidalgo, N. D. (2009). Bridges to success in high school for migrant youth. Teachers College Record, 111(3), 683-711.

Gilbert, K. M., Johnson, M., \& Plaut, J. (2009). Cultivating interdependent partnerships for community change and civic education. In J. R. Strait \& M. Lima (Eds.), The future of service learning: New solutions for sustaining and improving practice (pp. $33-51$ ). Sterling, VA: Stylus Publishing.

Glaser, B.G., Strauss, A.L., \& Strutzel, E. (1968). The discovery of grounded theory: Strategies for qualitative research. Nursing Research, 17(4), 353-368.

González, A. [Alejandro] (2013). Latino migrant parent influence on Latino migrant student university enrollment. (Unpublished Doctoral dissertation). California State University, Fullerton, Fullerton, CA.

Gonzalez, G.G. [Gilbert] (2013). Chicano education in the era of segregation (2 ${ }^{\text {nd }}$ Ed.). Denton, TX: University of North Texas Press.

Gonzalez, J. [Juan] (2011). Harvest of Empire: A History of Latinos in America. New York, NY: Penguin Books.

Graff, C.S., McCain, T., \& Gomez.-Vilchis., V. (2013). Latina resilience in higher education: Contributing factors including seasonal farmworker experiences. Journal of Hispanic Higher Education, 12(4), 334-344.

Greenberg, D. (2007). Science for sale: the perils, rewards, and delusions of campus capitalism. Chicago: University of Chicago Press.

Henry, S. E., \& Breyfogle, M. L. (2006). Toward a new framework of "server" and "served": De (and re)constructing reciprocity in service-learning pedagogy. International Journal of Teaching and Learning in Higher Education, 18(1), 27-35

Hérnandez-Wolfe, P. (2013). A borderlands view on Latinos, Latin Americans, and decolonization: rethinking mental health. Lanham, MD: Rowman \& Littlefield.

Holland, B. A. and Gelmon, S. B. (1998). The state of the "engaged campus": What we have learned about building and sustaining university-community partnerships. AAHE Bulletin 51(2), $3-6$.

Jameson, J., Clayton, P., \& Jaeger, A. (2010). Community engaged scholarship as mutually transformative partnerships. In L. Harter, J. Hamel-Lambert, \& J. Millesen (Eds.), Participatory partnerships for social action and research. Dubuque, IA: Kendall Hunt.

Jasis, P., \& Marriott, D. (2010). All for our children: Migrant families and parent participation in an alternative education program. Journal of Latinos and Education, 9(2), 126-140.

Kecskes, K. (2006). Behind the rhetoric: Applying a cultural theory lens to community-campus partnership development. Michigan Journal of Community Service-learning, 12(2), 5-14.

Le Poire, B. A., Hallett, J. S., \& Giles, H. (2009). Codependence: the paradoxical nature of the functional-afflicted relationship. In B.H. Spitzberg \& W.R. Cupach (Eds.), The Dark Side of Close Relationships, 153 - 176. Mahwah, NJ: Lawrence Erlbaum Associates.

Lopez, G. R. (2001). The value of hard work: Lessons on parent involvement from an (im)migrant household. Harvard Educational Review, 71(3), 416.

Lopez, G. R. (2004). Bringing the mountain to Mohammed: Parent involvement in migrantimpacted schools. In C. Salinas \& M. Fránquiz (Eds.), Scholars in the field: The challenges of migrant education (pp. 135 -146). Charleston, WV: ERIC Clearinghouse on Rural Education and Small Schools.

Lopez, G., Scribner, J. D., \& Mahitivanichcha, K. (2001). Redefining parental involvement: Lessons from high-performing migrant-impacted schools. American Educational Research Journal, 38(2), 253-288

McHatton, P., Zalaquett, C., \& Cranson-Gingras, A. (2006). Achieving success: Perceptions of students from migrant farmwork families. American Secondary Education, 34(2), 25-39. 
Mercer, J. (2007). The challenges of insider research in educational institutions: Wielding a double-edged sword and resolving delicate dilemmas. Oxford Review of Education, 33(1), 1-17.

Moll, L., Amanti, C., Neff, D. and Gonzalez, N. (1992). Funds of knowledge for teaching: Using a qualitative approach to connect homes and classrooms. Theory Into Practice, 31(2), 132-141.

Mora, J. \& Diaz, D. (2004). Latino social policy: a participatory research model. Binghamton, NY: Haworth Press.

National Safety Council. (2010). Stats services, most dangerous occupations. Retrieved from http://www.nsc.org/news_resources/Resources/res_stats_services/Pages/FrequentlyAsk edQuestions.aspx\#question5.

Nuñez, A. (2009). Creating pathways to college for migrant students: Assessing a migrant outreach program. Journal of Education for Students Placed at Risk, 14(3), 226-237.

Olssen, M. \& Peters, M. A. (2007). Neoliberalism, higher education and the knowledge economy from the free market to knowledge capitalism. Journal of Education Policy 20(3), $313-$ 345.

Ponjuan, L. (2011, Fall). Recruiting and retaining Latino faculty members: The missing piece to Latino student success. Thought \& Action, 99-110..

Quick, J. C. \& Macik-Frey, M. (2007). Healthy, productive work: Positive strength through communication competence and interpersonal interdependence. In L.D. Nelson \& C.L. Cooper (Eds.), Positive organizational behavior: Accentuating the positive at work (2539). Thousand Oaks, CA: SAGE.

Rendón, L. I. (2002). Community college puente: A validating model of education. Educational Policy, 16, 642-667.

Rendón, L. I. (1994). Validating culturally diverse students: Toward a new model of learning and student development. Innovative Higher Education, 19(1), 33-51.

Smith, L. T. (1999). Decolonizing methodologies: research and indigenous peoples. New York, NY: Zed Books.

Spring, J. (1994). Deculturalization and the struggle for equality: a brief history of the education of dominated cultures in the United States. New York, NY: McGraw-Hill.

Strauss, A. \& Corbin, J. (1990). Basics of qualitative research: Grounded theory procedures and techniques. Newbury Park, CA: Sage Publications.

Srinivasan, S. \& Collman, G.W. (2005). Evolving partnerships in communities. Environmental Health Perspectives, 113(2), 1814-1816.

Villanueva, S. T. (2013). Teaching as healing craft: Decolonizing the classroom and creating spaces of hopeful resistance through Chicano-Indigenous pedagogical praxis. The Urban Review 45(1), 23 - 40.

Valdés, G. (1996). Con respeto: Bridging the distances between culturally diverse families and schools: An ethnographic portrait. New York, NY: Teachers College Press.

Valenzuela, A. (1999). Subtractive schooling: U.S.-Mexican youth and the politics of caring. New York, NY: State University of New York Press.

Yosso, T.J. (2006). Critical race counterstories along the Chicana/Chicano educational pipeline. New York, NY: Routledge.

Yosso, T.J. (2005). Whose culture has capital? A critical race theory discussion of community cultural wealth. Race, Ethnicity, and Education, 8(1), 69-91.

Zalaquett, C., Alvarez McHatton, P., \& Cranston-Gingras, A. (2007). Characteristics of Latina/o migrant farmworker students attending a large metropolitan university. Journal of Hispanic Higher Education, 6(2), 135-156.

Zavala, M. (2013). What do we mean by decolonizing research strategies? Lessons from decolonizing, indigenous research projects in New Zealand and Latin America. Decolonization: Indigeneity, Education \& Society, 2(1), 55 - 71. 
Zavella, P. (1993). Insider dilemmas: Constructing ethnic identity with "Chicana" informants. Frontiers: a Journal of Women Studies, 13(3), 53-76. 


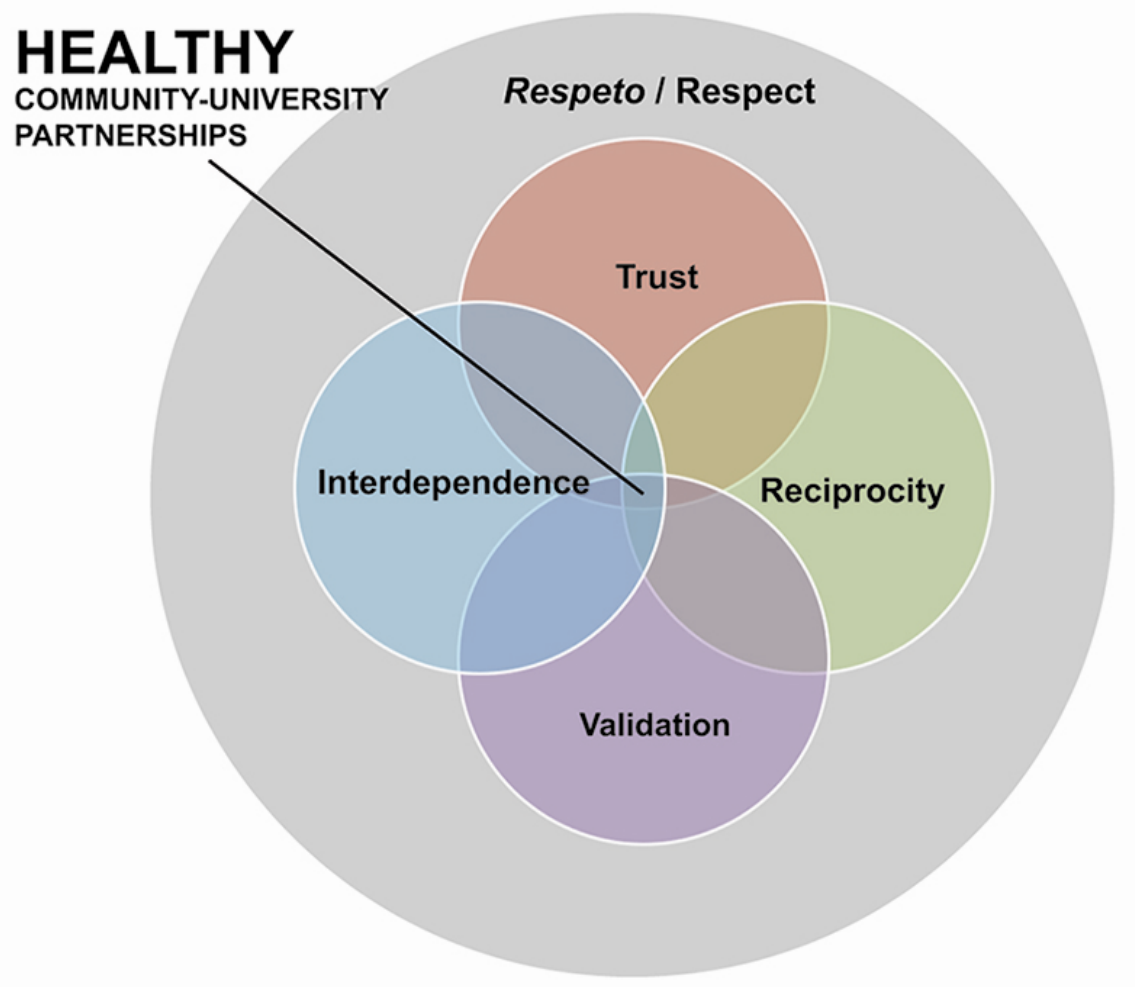

Figure 1. Healthy community-university partnerships. This figure highlights the inter-relationship of dimensions of healthy community-university partnerships. 